\title{
Investigation on the mass sensitivity of quartz crystal microbalance gas sensor using finite element simulation
}

\author{
Aliza Aini Md Ralib, Nik Nursyahida Bt Nik Mohd Zamri, Ahmad Hafiz Faqruddin Hazadi, \\ Rosminazuin Ab Rahim, Nor Farahidah Za'bah, Norazlina Saidin \\ Department of Electrical and Computer Engineering, Faculty of Engineering International Islamic University \\ Malaysia, Malaysia
}

\section{Article Info}

Article history:

Received Jan 7, 2019

Revised Feb 18, 2019

Accepted Mar 25, 2019

Keywords:

Breath analysis

QCM sensor

Piezoelectric

Sensitivity

\begin{abstract}
The increasing global trends in healthcare priorities towards improving the effectiveness of diagnostic procedure by utilizing a non-invasive method which is breath analysis. This will benefit in increasing treatment efficiency and also reducing healthcare costs. Breath is a simple technique where the sample are easily obtained and can be provided immediately. The most popular method that had been used in hospital are urine and blood. Contradict with breath, urine and blood take too much time to analyse the disease and a painful process. The detection technique of breath analysis is done by using electroacoustic wave sensor from piezoelectric substrate. This acoustic wave sensor has been used to detect the changes in the frequency where it will be used to detect the disease. Breath analysis is a technique where it uses an electronic nose (E-nose) as a device. E-nose consist of Quartz Crystal Microbalance (QCM) sensor in order to differentiate odor in human breath. QCM is a sensitive weighing device which have a high efficiency. AT-cut quartz was chosen as the piezoelectric material and aluminum as the electrode. The objective of this paper is to design and simulate a QCM sensor for breath analysis application. Other than that, it also to determine the important key parameters that influence the performance of breath analysis which is sensitivity and resonant frequency. QCM sensor is being simulate by using COMSOL Multiphysics software. This is to evaluate the behavior of QCM sensor in terms of Eigen frequency analysis. The simulated QCM sensor with quartz radius of 166 um resonates at $8.871 \mathrm{MHz}$. The sensitivity of the sensor is $0.167 \mathrm{MHz} / \mathrm{ng}$ after exposed to acetone gas which act as the breath marker for detection of diseases in exhaled breath. Hence, the proposed design can be used as a non-invasive approach for early detection of disease through breath analysis.
\end{abstract}

Copyright @ 2019 Institute of Advanced Engineering and Science. All rights reserved.

\section{Corresponding Author:}

Aliza Aini Md Ralib,

Department of Electrical and Computer Engineering,

Faculty of Engineering,

International Islamic University Malaysia, Malaysia.

Email: alizaaini@iium.edu.my

\section{INTRODUCTION}

According to the World Health Organization (WHO) in 2015, the majority of death are caused by the four main noncommunicable disease (NCD) which are cardiovascular disease, cancer, chronic respiratory disease and diabetes. The highest cause of death among all these four diseases is cardiovascular disease which is 17.7 million deaths (45\%) [1]. NCDs caused $70 \%$ of deaths globally where the highest statistic of death is in high-income countries which is $88 \%$ while only $37 \%$ from low income countries [2]. Measuring the reason of the death and the statistic is important as this can help health authorities to take health action. 
The first measure that can be taken by health authorities is by diagnosing the patient's health. However, diagnoses in today's clinical solution is quite costly and it takes too much time to be done. People in high-income countries will avoid cumbersome procedure as it will takes too much of their valuable time. Other than that, it is also a hurtful procedure by using blood as they need to draw blood from patient's body.

Thus, researchers have been seeking for a solution to solve this problem. As the technology in clinical diagnosis moved forward, a solution have been found by researchers to improve the effectiveness of diagnostic procedures by introducing a non-invasive method which is breath analysis. Breath is the most applicable method for disease detection as all human beings need to breath in order to live. Breath analysis functioning by detecting volatile organic compound (VOC) from patient's breath [3]. Illness can be diagnosed by detecting the differences in the gas components concentration. In order to diagnose a disease, breath markers have been discovered from the human's breath. Different breath markers will detect different disease. Nowadays, in the medical world there are a lot critical diseases that need a high efficiency device to help medical team to analyze diseases with a short of time. In today's clinical solution, the patient's need to use blood and also urine to diagnose the disease. As the problem with today's clinical solution takes too much time to analyze the disease and also painful to draw blood from the patient's body, researchers took initiation to solve this problem. Thus, new devices that only using breath have been introduced, called electronic nose (E-nose) and also gas chromatography [4]. In gas chromatography, the reason why it is not preferable as the device has a limitation, bulky and also expensive. It is also a complex instrument that consume too much time to detect the disease. Thus, E-nose has been chosen as the most efficient device to replace the invasive method which is blood and urine to non-invasive method which is by breath odor [5].

Electronic nose is a device which is simple, low cost and also portable device. In electronic nose, it consists of Quartz Crystal Microbalance (QCM) sensor in order to differentiate odor in human breath. The significance of QCM sensor is that it can imitate the mammalian nose that could reenact mammalian olfactory responses to smells. QCM have been selected to use in this device instead of other sensor is that it is an ultrasensitive weighing device. It also have high efficiency compared to other sensor in Gas Chromatography. Breath is a non-invasive approach for analysis and favored over blood and urine specimens [6]. The problem with today's clinical solution such as blood and urine and invasive [7]. As the technology in clinical diagnosis moved forward, researchers have found a solution to improve the effectiveness of diagnostic procedures by utilizing non-invasive methods which is breath analysis. As the diagnostic based on breath analysis are being developed, definitely there are advantages and disadvantages towards this test In breath analysis, breathing can be analyzed as exhaled breathing gas or exhaled breathing condensate. Collection through gas sampling in a gas bag is substantially more popular than the breath condensate method [8]. The first step for the breath test is to collect exhaled breath from a patient. From the exhaled breath, the breath marker will detect the composition of volatile organic compound by the sensor in electronic nose to detect the specific disease. The next process will go through sample collection/preparation and analysis.

The analysis of volatile organic compounds are used as the biomarker for breath analysis for noninvasive disease detection methods. Sensors are chosen for breath analysis as they are smaller and portable compared to laboratory diagnostic equipments [9]. Many attempts also have investigated the volatile organic compound sensing using quartz crystal microbalance (QCM) sensors and thin film bulk acoustic wave resonators [10]. QCM is the best among sensors to identify a wide range of (VOCs) for the quick response and also excellent sensitivity [11-16]. Previous work reported the detection of blood glucose by sensing the acetone as the biomarker. 30 patients were tested to detect the blood glucose. In this experiment, patient's breath is detected by using electronic nose. An electronic nose mimic the animal's nose as it has the ability to identify volatile chemical in surrounding. This experiment is done by detecting blood glucose and HbA1c level in patient's odor to detect diabetes illness. Data for this study were collected using AT-Cut quartz piezoelectric material which the thickness is $166.1 \mu \mathrm{m}$. The resonant frequency for this device is 10 MHz. The type of electrode used in this experiment is gold plated with $3 \mathrm{~mm}$ diameter and coated with phthalocyanine solutions. This study has shown that the changes in frequency is in the range $5484-7300 \mathrm{~Hz}$ for the glucose while $572-768 \mathrm{~Hz}$ for the HbA1c [14]. The present of acetone gas in exhaled breathing odor is sensed using QCM sensor to detect diabetes disease. The capability of QCM sensor to analyses the data in actual time making them been utilized in a wide range of applications [17-19]. From the composition of breath, patients that suffer with lung cancer can be detected by using electronic nose. This device that was used consist of 8 quartz microbalance (QMB) gas sensor cover with diverse metalloporphyrins. Metalloporphyrins were used as sensing element due to the magnificent ligands for metal ions. In this research, 60 people has participated. A total of 35 were suffering from lung cancer, 18 participants as reference and 9 of them were evaluated after surgical therapy. This test takes time about 5 weeks. As the result, the volatile compounds in the breath samples were not detected in the healthy participant [20]. 
Overall, these researches have shown that quartz crystal microbalance (QCM) has been gain interest as it widely employed in many areas due to the outstanding performance. From the previous studies, it has been shown that QCM has a very high sensitivity to the mass changes. Thus, it is proven that QCM is highly suitable to use as a sensor due to its sensitivity [21]. In this paper, the design and optimization of a QCM sensor for breath analysis using finite element simulation is presented. The thickness of piezoelectric material is affecting the frequency change in the fundamental oscillation frequency as it is inversely proportional. Other than that, the area and the shape of the electrode can also affect the performance of the sensor. This interesting phenomenon requires further investigation. Hence, the objective of this paper is to investigate the mass sensitivity of quartz crystal microbalance sensor. For this purpose, the finite element simulation was conducted. The rest of the paper is organized as follows. Section 2 explains an overview on design concept and performance. Section 3 gives the details on the finite element simulation of the QCM sensor. Section 4 presents the simulation results. Finally, a conclusion is given in Section 5.

\section{DESIGN CONCEPT}

Piezoelectricity is the capability of converting from electrical (voltage) into mechanical signal and the other way around. When voltage is applied, mechanical signal will be produced in piezoelectric device [22]. Consequently, mechanical signal will be converting backwards to voltage. The piezoelectric sensor used in gas sensing consists of two types, which are the quartz crystal microbalance (QCM) and the surface acoustic wave (SAW) device [21]. The QCM creates a wave that travels along the bulk of the sensor while the SAW device creates a surface wave that travels through the surface of the sensor [21]. Both types of sensors follow the principle that the mass changing of the piezoelectric sensor coating is due to the gas absorption, which results in a change of the resonant frequency of exposure to a gas.

QCM is a simple device that has excellent sensitivity. QCM sensor contains a piezoelectric material which is quartz and sandwiched between two electrodes. When a voltage which is electrical signal that consist of electron is applied to the electrode, the piezoelectric effect will convert the electrical signal into mechanical vibration in terms of acoustic wave [22,23]. Then, the mechanical vibration will be converted back to the electrical signal. When a surface on QCM is being touched by a gas, the changes of mass will be occurred as the particle combined in the film. This will be effecting the changes in the frequency. In QCM sensor, the principle of the sensor is based on the changes in frequency to analyze the result of the experiment [12].

$$
\Delta C_{g a s} \Rightarrow \Delta m \Rightarrow \Delta f
$$

where: $\Delta C$ gas $=$ concentration of gas

$\Delta m=$ changes in mass $(\mathrm{g})$

$\Delta f=$ frequency change $(\mathrm{Hz})$

The performance of a QCM sensor can be determined by resonant frequency, sensitivity and coupling coefficient.

\subsection{Resonant frequency}

Resonant frequency, $f r$ is defined as the specific frequency when acoustic wave oscillates at higher amplitude. The dimension of piezoelectric material will determine $f_{r}$. It is determined by using mathematical formula where $v$ is velocity and $d$ is the dimension in thickness of piezoelectric material as shown in (1).

$$
f_{r}=\frac{v}{2 d}
$$

\subsection{Sensitivity}

The fundamental of QCM sensor is totally depending on the frequency shift because of the changes in mass. This sensitivity can be calculated using (2) where frequency change is denoted in $\Delta \mathrm{f}, c f$ is the quartz mass sensitivity, A is sensitivity of area, $\Delta m$ is the change in mass, and $f 0$ is resonant frequency of quartz [14].

$$
S=\frac{\Delta f}{\Delta m}=-\frac{c_{f} f_{o}}{A}
$$

From (2), it can be summarized as when there is a change in the layer, the frequency change will be affected. This is because the relationship between them is inversely proportional. 


\subsection{Coupling coefficient}

Coupling coefficient is a no magnitude value that calculate the effectiveness of piezoelectric to convert from mechanical signal to electrical signal. The value of coupling coefficient is calculated using (2) and (3), where fp is the parallel resonance frequency and fs is the series resonance frequency.

$$
k^{2}=\left(\frac{\pi^{2}}{4}\right)\left(\frac{f_{p}-f_{s}}{f_{p}}\right)
$$

\section{RESEARCH METHOD}

\subsection{Before sensing}

The proposed design was simulated using COMSOL Multiphysics. Frequency domain and eigen frequency analysis was done to compute the maximum displacement, resonance frequency and coupling coefficient. Eigen frequency analysis was performed to provide eigen values which shows the resonant frequency of the design. The electrode that been used in this project is AT-Cut quartz piezoelectric material. Therefore, the resonant frequency of this QCM sensor is $10 \mathrm{MHz}$. The device dimension of the proposed design is shown in Table 1. Figure 1 shows the cross section of the proposed design that consists of top electrode, quartz as the piezoelectric layer and gold bottom electrode. The 3D view of the QCM sensor and the mesh analysis were displayed in Figure 1(b) and Figure 1(c) respectively.

Table 1. Proposed design

\begin{tabular}{cc}
\hline Parameter & Value \\
\hline Piezoelectric Material & AT Cut Quartz \\
Piezoelectric Thickness, tp & $166 \mu \mathrm{m}$ \\
Electrode Material & Gold (Au) \\
Resonant Frequency, $f r$ & $10 \mathrm{MHz}$ \\
Acoustic wave velocity Quartz, $\mathrm{v}$ & $3322 \mathrm{~m} / \mathrm{s}$ \\
Length and width of AT cut quartz & $1670 \mu \mathrm{mx} 1670 \mu \mathrm{m}$ \\
Length and width of AT cut quartz & $1000 \mu \mathrm{mx} 1000 \mu \mathrm{m}$ \\
Electrode thickness & $0.2 \mu \mathrm{m}$ \\
\hline
\end{tabular}

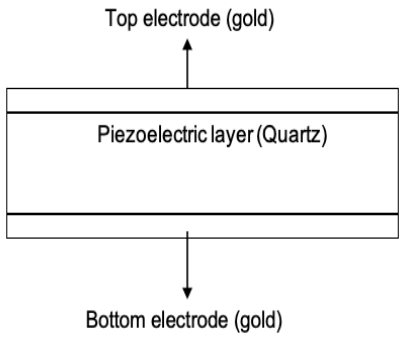

(a)

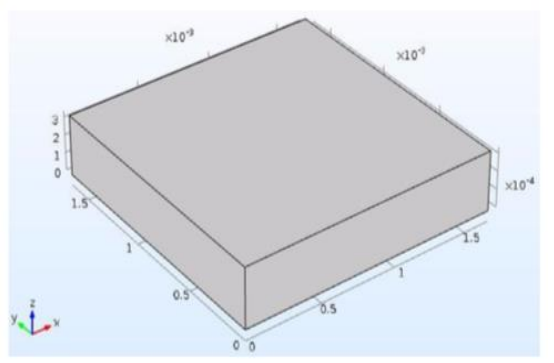

(b)

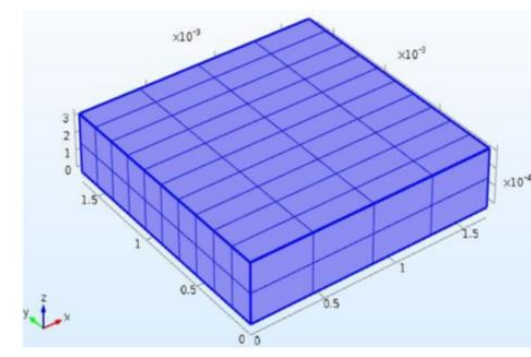

(c)

Figure 1. Model geometry of the COMSOL Multiphysics simulation, (a) Cross section of proposed design, (b) Geometry of square QCM sensor, (c) Mesh analysis with perfect matched layer

\subsection{After sensing}

For the sensing gas, this work is focused on the breath analysis and acetone gas was chosen as the sensing gas. This is because acetone gas is the potential biomarker for diabetes detection through breath. Current technique to diagnosis and monitoring blood glucose involve pricking fingers for blood test. This method is invasive and painful. Hence, excess amounts of acetone that is exhaled breath during are produced for patients with diabetes [24]. Figure 2 shows the model geometry after sensing. The performance of the QCM sensor is depends on the type of sensing films coated on the electrodes. Many type of sensing layers such as zeolites, polymer, carbon graphites and zeolites able to sense acetone vapors [25]. In this work, polymer was added on the QCM sensor to selectively adsorb the acetone gas as shown in Figure 2(a). Figure 2(b) shows the mesh analysis for the QCM sensor after sensing. 


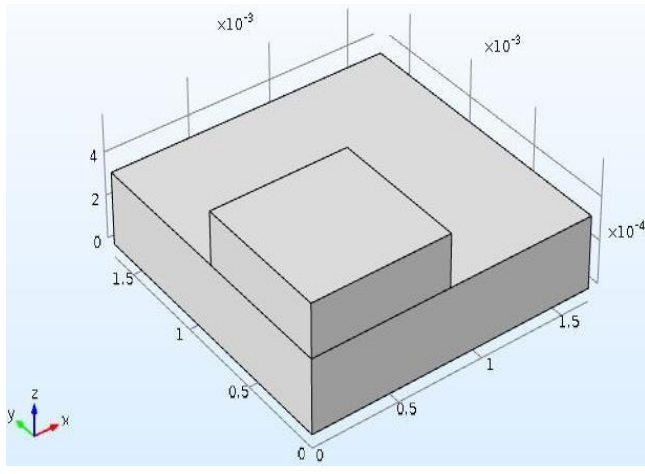

(a)

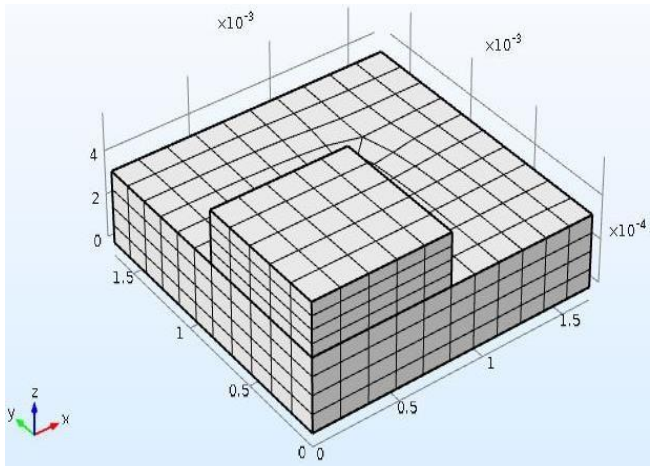

(b)

Figure 2. Model geometry after sensing, (a) Geometry of QCM sensor after sensing, (b) Mesh analysis with perfect matched layer

\section{RESULT AND DISCUSSION}

\subsection{Before sensing}

This section discussed the results obtained from the simulation of COMSOL Multiphysics. This simulation consists of two parts which are before sensing simulation and after sensing simulation. Simulation starts with the select geometry and square shape has been chosen for QCM sensor structure. Then, material can be selected at the Add Material toolbar to insert the needed material for QCM sensor. Next, electrostatics part is for the terminal and ground selection of the model. Lastly for mesh analysis, the model is divided into discrete components to get more accurate result in term of frequency. The analyzed results are displacement and figure for different thickness of quartz. In this simulation, there are 6 different thickness of quartz that varies from $50 \mu \mathrm{m}$ to $400 \mu \mathrm{m}$. The contour plot for displacement of QCM sensor is shown in Figure 3 for different piezoelectric thickness of $50 \mu \mathrm{m}, 100 \mu \mathrm{m}$ and $250 \mu \mathrm{m}$. The resonance frequency shown is 32.475 $\mathrm{MHz}, 15.64 \mathrm{MHz}$ and $6.495 \mathrm{MHz}$ as predicted in the theory calculation from (1).

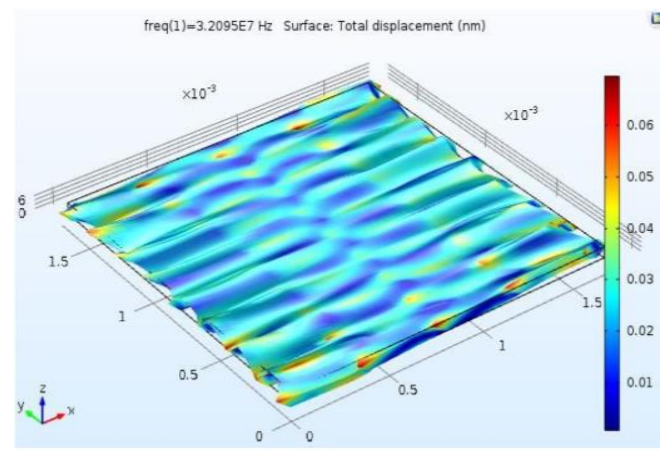

(a)

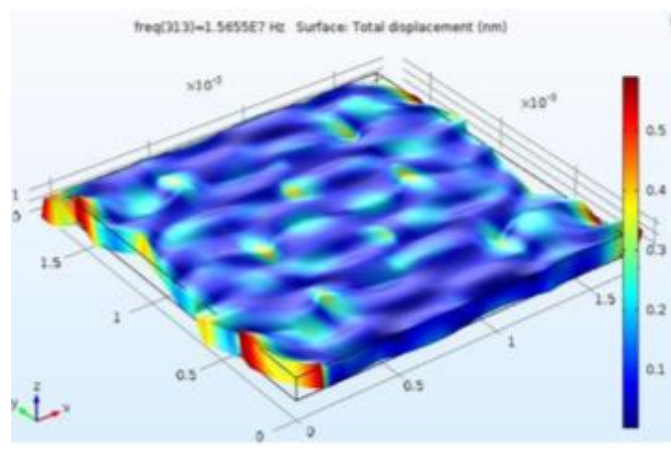

(b)

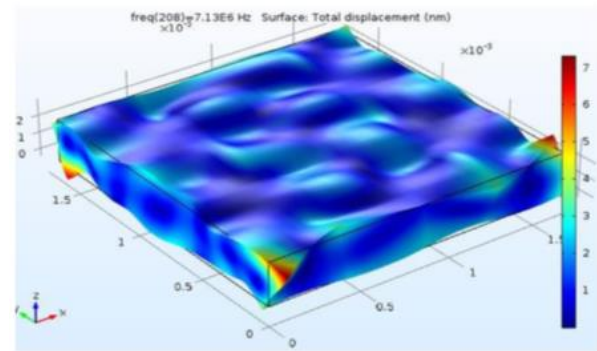

(c)

Figure 3. Contour plot for displacement for with different quartz thickness, $d$, (a) $d=50 \mu \mathrm{m}$, (b) $d=100 \mu \mathrm{m}$, (c) $d=250 \mu \mathrm{m}$ 
The results from this simulation shows graph of displacement in frequency domain analysis. Displacement graph is a crucial part to obtain resonant frequency value. This resonant frequency varied along the piezoelectric thickness. It can be presumed that when the thickness of quartz is enlarged, the value for resonant frequency will be reduced. Figure 4 demonstrates the graph of resonant frequency versus thickness of quartz. From the graph, it can be concluded that as the thickness of resonant frequency increase, the resonant frequency will decrease. The highest value of resonant frequency is $32.475 \mathrm{MHz}$ at $50 \mu \mathrm{m}$ while the lowest is 3.560 at $400 \mu \mathrm{m}$. Thus, the thickness of quartz is inversely proportional with resonant frequency. The highest resonant frequency achieved is $32.475 \mathrm{MHz}$ for piezoelectric thickness of $50 \mu \mathrm{m}$.

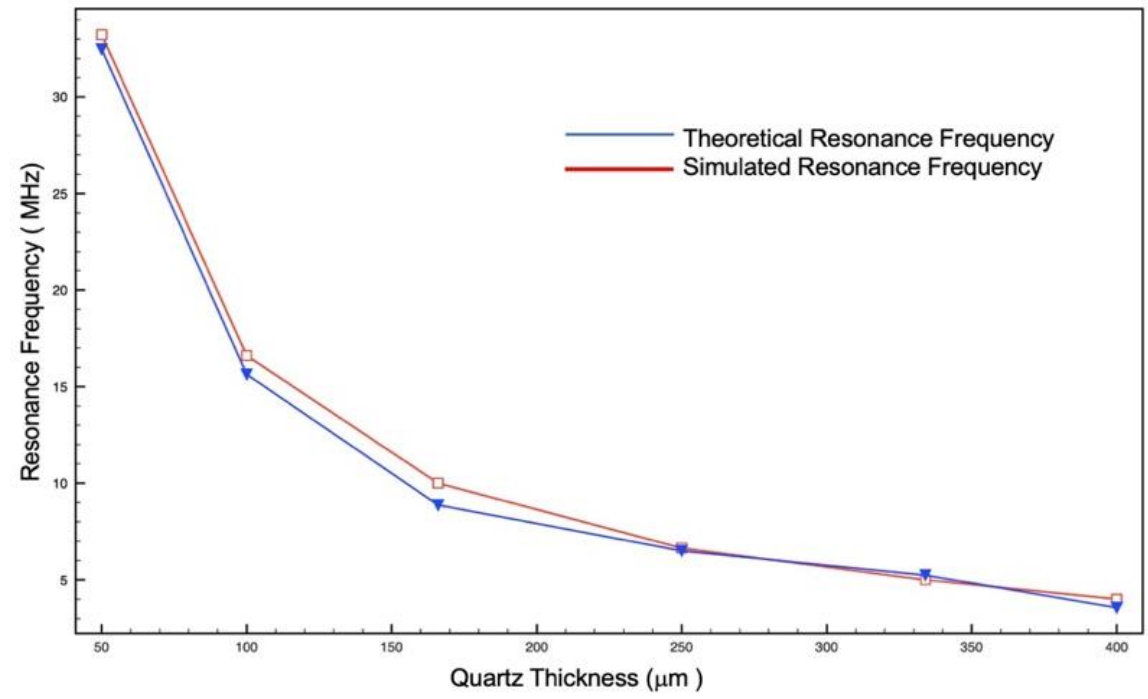

Figure 4. Quartz thickness vs simulated and theoretical resonance frequency before sensing

This displacement graph also provides the parallel resonance frequency, $f p$ and series resonance frequency, $f s$ as shown in Figure 5. Coupling coefficient is the magnitude value that calculate the effectiveness of piezoelectric to convert from mechanical signal to electrical signal. Next, the formula (3) is used to calculate the value of coupling coefficient, $\mathrm{k} 2$. The higher the thickness of piezoelectric material, the higher the electromechanical coupling coefficient. The most optimum value of coupling coefficient acquired is 0.00691 with piezoelectric thickness $400 \mu \mathrm{m}$ as displayed in Figure 6.

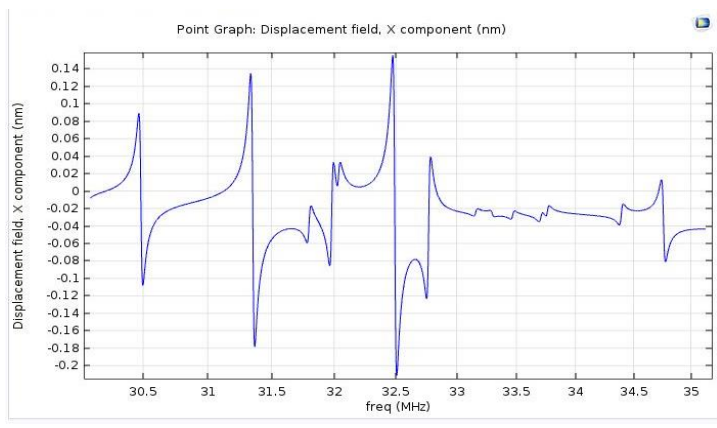

(a)

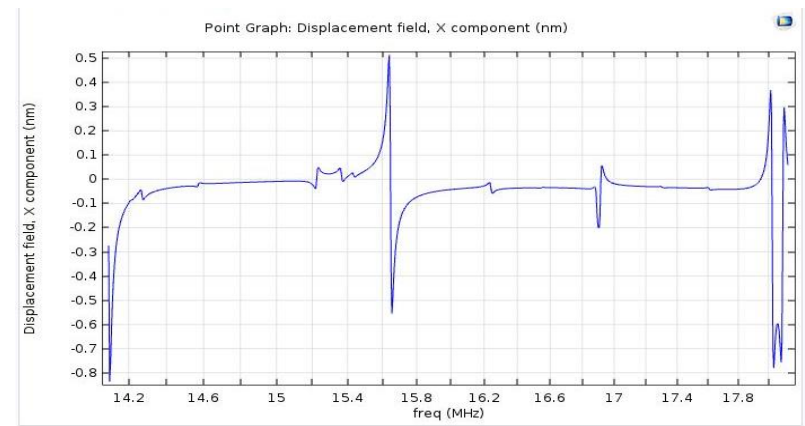

(b) 


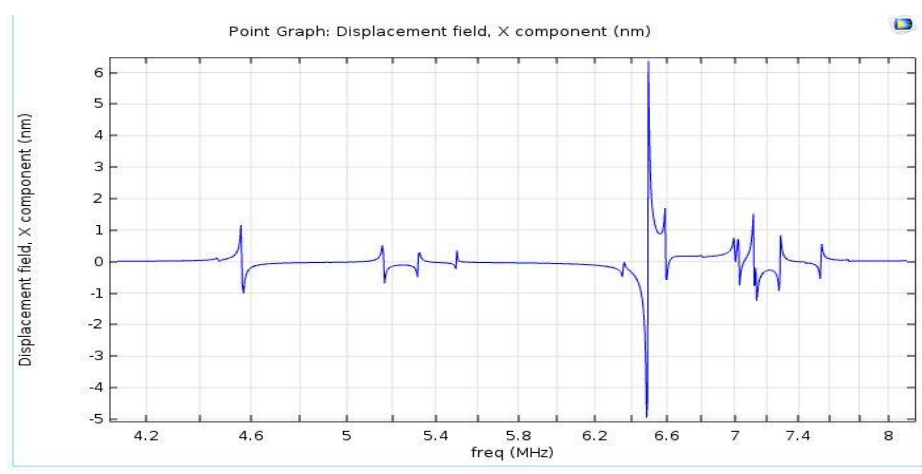

(c)

Figure 5. Frequency vs admittance before sensing with different quartz thickness, $d$, (a) $d=50 \mu \mathrm{m}$, (b) $d=100$ $\mu \mathrm{m}$, (c) $d=250 \mu \mathrm{m}$

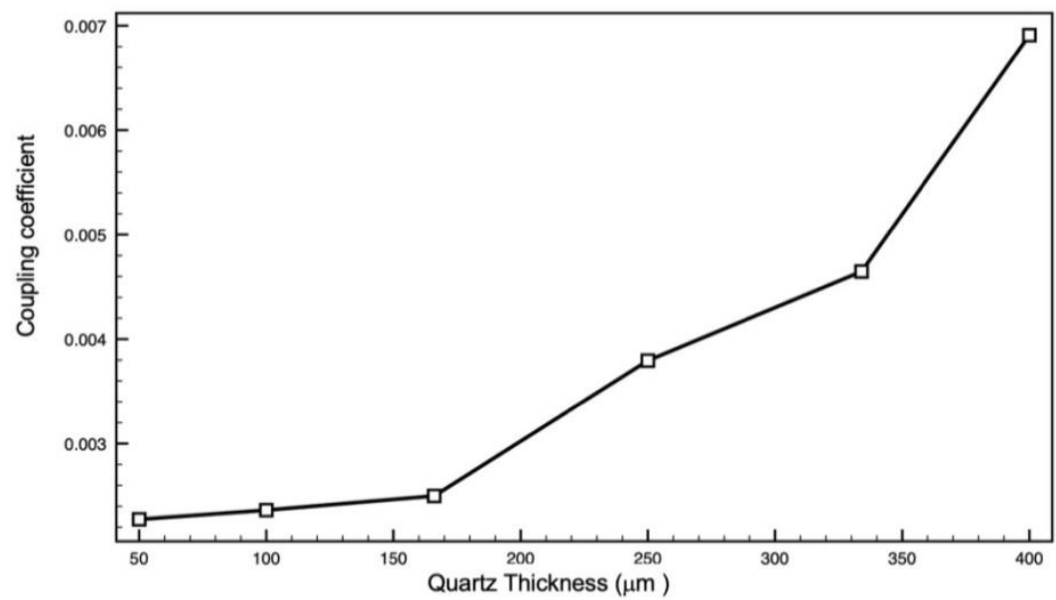

Figure 6. Quartz thickness vs coupling coefficient before sensing

\subsection{After sensing}

For the sensing gas, this work is focused on the breath analysis and acetone gas was chosen as the sensing gas. This is because acetone gas is the biomarker for diabetes detection through breath. In this section, analysis of simulation results for Quartz sensor with acetone gas will be reviewed. The variation of area of quartz from $435 \mu \mathrm{m}$ to $1435 \mu \mathrm{m}$. Sensitivity can be calculated using (5). As the area get bigger, the value of sensitivity decreasing. It also can be proven by using the Sauerbrey's (2). In conclusion, the relationship between sensitivity and area of quartz is inversely proportional. From Figure 7, the highest sensitivity is when the area of quartz is $435 \mu \mathrm{m}$ which is $16.014 \mathrm{MHz} / \mathrm{ng}$ while the lowest sensitivity is at $1435 \mu \mathrm{m}$ area of quartz where the sensitivity value is $8.81 \mathrm{MHz} / \mathrm{ng}$.

In this section the effect of density of acetone gas toward the frequency changes is discussed. The density of acetone gas is diversified from 10 to $50,000 \mathrm{~kg} / \mathrm{m} 3$. The frequency before sensing of Quartz sensor is $8.871 \mathrm{MHz}$ and the frequency after sensing is changing with the density of acetone gas due to mass loading. By finding the slope of plotting mass changes versus frequency changes graph, the mass sensitivity of Quartz sensor can be attained. In order to calculate mass changes, $\Delta \mathrm{m}$, (4) can be used while the frequency change, $\Delta \mathrm{f}$ can be found. Hence, by using the formula below, the mass sensitivity can be acquired. Figure 8 illustrates the relation between frequency changes and mass changes due to the variation in density of acetone gas. From the analysis, it can be observed that the coupling coefficient for optimum design is 00.002499 at $166 \mu \mathrm{m}$ of quartz thickness and the resonant frequency at $8.871 \mathrm{MHz}$. This result is following with the mass sensitivity for simulation is $0.1672 \mathrm{MHz} . \mathrm{cm}^{2} / \mathrm{g}$. 


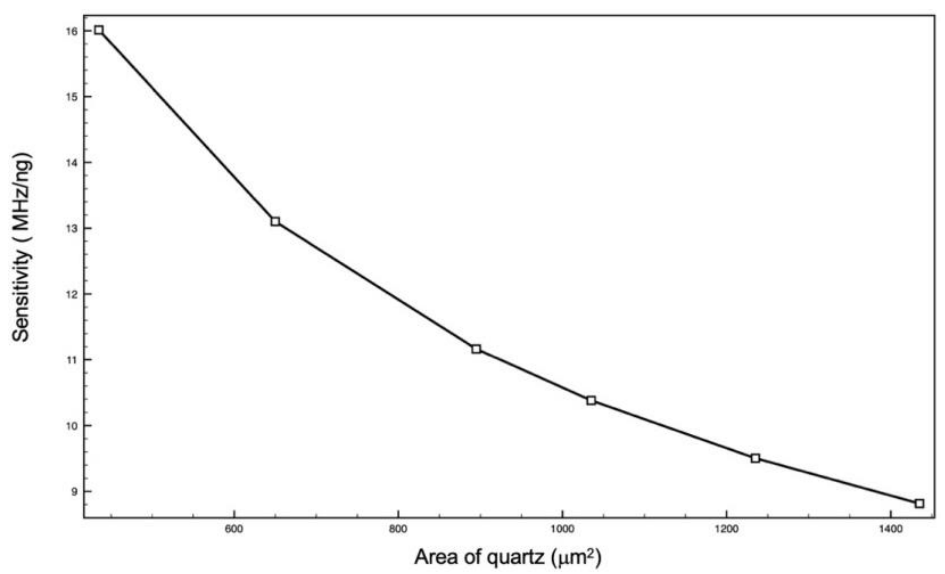

Figure 7. Area of quartz vs mass sensitivity after sensing

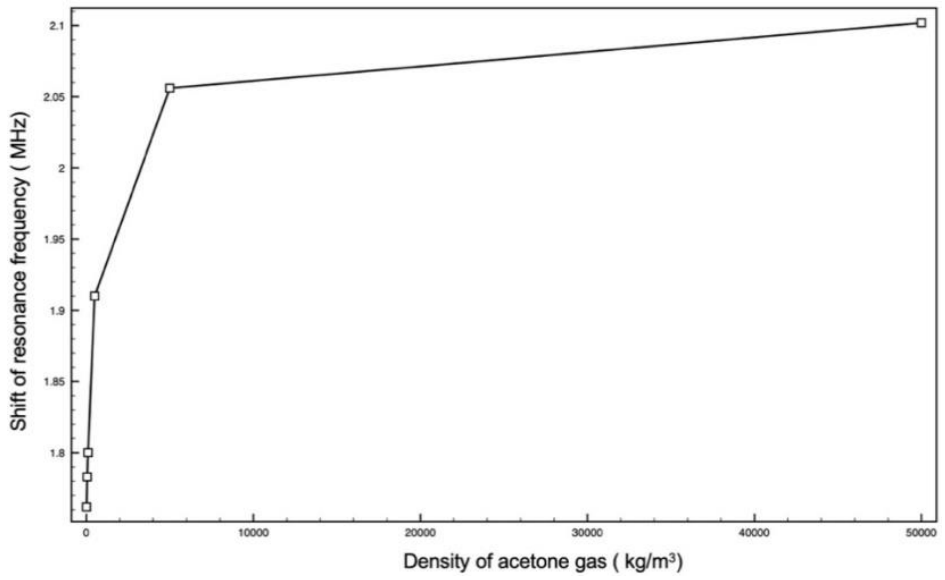

Figure 8. Density of acetone gas vs shift of resonance frequency after sensing

\section{CONCLUSION}

An investigation has been made on the mass sensitivity of the QCM sensors are studied via finite element simulation. 2D finite element modelling using COMSOL Multiphysics is presented. The simulation result shows that the relationship between sensitivity and area of quartz is inversely proportional. Piezoelectric material has been encountering a worldwide requirement development in the industrial and manufacturing market these days. There are lots of fields showing interest and enthusiasm such as engineering and medical field. Plus, being in the medical field, the utilization of QCM sensor can definitely be evolved. A few suggestions can be used to be implemented on the QCM sensor device. First and foremost, instead of acetone gas, another gas substance can be evaluated for the testing gas on Quartz sensor. This will differentiate between different valued of mass sensitivity of different gas. Therefore, if the breath analysis using an FBAR device, it can identify which type of gases being released by the patient according to the different mass sensitivity value and various types of diseases can be distinguished. It is with high hope that this research can be useful for the humankind in order for us to advance forward.

\section{ACKNOWLEDGEMENTS}

This research was supported by IIUM Research Initiative Grant Scheme (RIGS16-083-0247) and Fundamental Research Grant Scheme (FRGS 17-032-0598) under International Islamic University Malaysia and Ministry of Higher Education Malaysia.

\section{REFERENCES}

[1] World Health Organization, World Health Statistics 2017,: Monitoring Health for The SDGs. 2017. 
[2] World Health Organization (WHO), "The top 10 causes of death," 2018. [Online]. Available: http://www.who.int/mediacentre/factsheets/fs310/en/.

[3] W. Cao and Y. Duan, "Breath analysis: Potential for clinical diagnosis and exposure assessment," Clinical Chemistry, vol. 52, no. 5, pp. 800-811, 2006.

[4] A. D. Wilson, "Electronic-nose devices - Potential for noninvasive early disease-detection applications," Annals of Clinical Case Reports, vol. 2, pp. 14-16, 2017.

[5] D. Wilson and M. Baietto, "Advances in electronic-nose technologies developed for biomedical applications," Sensors, vol. 11, no. 1, pp. 1105-1176, 2011.

[6] J. Gardner and T. Vincent, "Electronic Noses for Well-Being: Breath Analysis and Energy Expenditure," Sensors, vol. 16, no. 7, pp. 947, 2016.

[7] Germanese, M. Righi, M. Guidi, M. Magrini, M. D'Acunto, and O. Salvetti, "A Device for Self-monitoring Breath Analysis," SENSORDEVICES 2016 : The Seventh International Conference on Sensor Device Technologies and Applications, 2016, pp. 77-82.

[8] W. Shin, "Medical applications of breath hydrogen measurements," Analytical and Bioanalytical Chemistry, vol. 406, no. 16, pp. 3931-3939, 2014.

[9] G. Konvalina and H. Haick, "Sensors for breath testing: From nanomaterials to comprehensive disease detection," Accounts of Checmical Research, vol. 47, no. 1, pp. 66-76, 2014.

[10] M. Dubois, "Thin film bulk acoustic wave resonators: a technology overview," MEMSWAVE, pp. 4-7, 2007.

[11] Ihdene, Zaher, et al. "Quartz crystal microbalance VOCs sensor based on dip coated polyaniline emeraldine salt thin films." Sensors and Actuators B: Chemical 203 (2014): 647-654.

[12] C. Di Nucci et al., "A measurement system for odor classification based on the dynamic response of QCM sensors," in IEEE Transactions on Instrumentation and Measurement, vol. 52, no. 4, pp. 1079-1086, Aug. 2003.

[13] J. Zhang, J. Liang and T. Ueda, "Design and evaluation of a dual channel high frequency Quartz crystal Microbalance," 2016 10th International Conference on Sensing Technology (ICST), Nanjing, 2016, pp. 1-5.

[14] H. M. Saraoğlu, A. O. Selvi, M. A. Ebeoğlu and C. Taşaltin, "Electronic Nose System Based on Quartz Crystal Microbalance Sensor for Blood Glucose and HbA1c Levels From Exhaled Breath Odor," in IEEE Sensors Journal, vol. 13, no. 11, pp. 4229-4235, Nov. 2013.

[15] S. K. Vashist and P. Vashist, "Recent advances in quartz crystal microbalance-based sensors," Sensors, vol. 2011, pp. 1-13, 2011.

[16] H. M. Saraoglu and M. Kocan, "Determination of Blood Glucose Level-Based Breath Analysis by a Quartz Crystal Microbalance Sensor Array," in IEEE Sensors Journal, vol. 10, no. 1, pp. 104-109, Jan. 2010.

[17] Saraoğlu, H.M., Özmen, A. \& Ebeoğlu, "Anesthetic level prediction using a QCM based E-Nose," Journal of Medical Systems, vol. 32, no. 3, pp. 251-257, 2008.

[18] Lijiang Wang et al., "Detection of E. coli O157:H7 DNA by a novel QCM biosensor coupled with gold nanoparticles amplification," 2007 7th IEEE Conference on Nanotechnology (IEEE NANO), Hong Kong, 2007, pp. 330-333.

[19] H. Huang, J. Zhou, S. Chen, L. Zeng, and Y. Huang, "A highly sensitive QCM sensor coated with Ag+-ZSM-5 film for medical diagnosis," Sensors Actuators, B Chem., vol. 101, no. 3, pp. 316-321, 2004.

[20] Di Natale et al., "Lung cancer identification by the analysis of breath by means of an array of non-selective gas sensors," Biosensors and Bioelectronics, vol. 18, no. 10, pp. 1209- 1218, 2003.

[21] A. H. F. Hazadi, A. A. M. Ralib and N. Saidin, "Design and Simulation of Electroacoustic Sensor for exhaled breath analysis," 2018 7th International Conference on Computer and Communication Engineering (ICCCE), Kuala Lumpur, Malaysia, 2018, pp. 388-391.

[22] Aliza Aini Md Ralib and Anis Nurashikin Nordin "Silicon compatible Acoustic wave resonators: Design, fabrication and performance," IIUM Engineering Journal, vol. 15, no. 2, pp. 23-41, 2014.

[23] Anifatul Faricha, Suwito Suwito, M. Rivai, M.A. Nanda, Djoko Purwanto, Rizki Anhar R.P. "Design of electronic nose system using gas chromatography principle and Surface Acoustic Wave sensor". TELKOMNIKA (Telecommunication, Computing, Electronics and Control), vol. 16, no.4, pp. 1457-1467, August 2018.

[24] Saasa, Valentine et al. "Sensing Technologies for Detection of Acetone in Human Breath for Diabetes Diagnosis and Monitoring" Diagnostics (Basel, Switzerland) vol. 8,1 12. 31 Jan. 2018, doi:10.3390/diagnostics8010012

[25] H. M. Saraoglu and M. Kocan, "Determination of Blood Glucose Level-Based Breath Analysis by a Quartz Crystal Microbalance Sensor Array," in IEEE Sensors Journal, vol. 10, no. 1, pp. 104-109, Jan. 2010.

\section{BIOGRAPHIES OF AUTHORS}

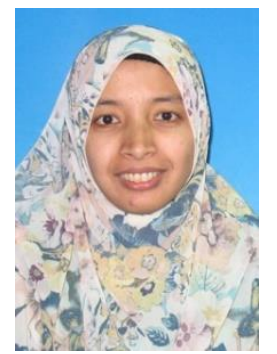

Aliza Aini Md Ralib was born in Johor, Malaysia in 1982. She obtained her B. Eng. in Computer and Information Engineering (Electronics) from International Islamic University Malaysia in 2006. Both her MSc and PhD in Electronics Engineering are also from IIUM in 2011 and 2016 respectively. From 2009 to 2016, she was a Research Assistant at Universiti Tenaga Nasional Malaysia and IIUM. Since 2016, she has been Assistant Professor with the Electrical and Computer Engineering Department, International Islamic University Malaysia. Her research interests include Micro Electro-mechanical (MEMS), CMOS-MEMS acoustic wave resonators, electroacoustic sensors, piezoelectric thin film and MEMS piezoelectric energy harvesting. Upon completion of her $\mathrm{PhD}$, she decided to work on developing on surface acoustic wave sensors for 
breath analysis as noninvasive solution for early detection of critical disease. Her work has been published both locally and internationally in more than 34 papers in journals and proceedings locally and internationally. She has been awarded IEEE Postgraduate Award of Excellence in Outstanding Project in MEMS and Nanoelectronics organized by IEEE Electron Devices Society Malaysia Chapter in 2016.
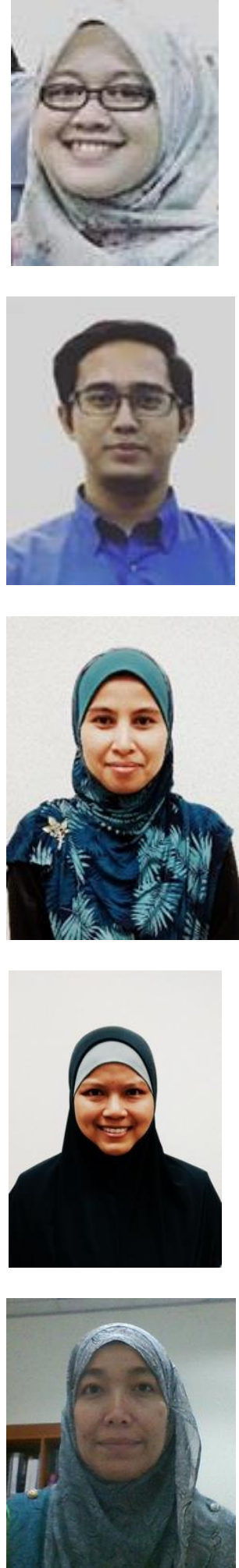

Nik Nursyahida Bt Nik Mohd Zamri obtained her B. Eng. in Computer and Information Engineering (Electronics) from International Islamic University Malaysia in 2018. Her final year project title is Design of electric nose based on quartz crystal microbalance sensor. She has been awarded the best final year project for IEEE Electron Devices Society Malaysia Chapter track in 2018 .

Ahmad Hafiz Faqruddin Hazadi obtained her B. Eng. in Computer and Information Engineering (Electronics) from International Islamic University Malaysia in 2018. His final year project title is design and simulation of electroacoustic sensor for breath analysis.

Rosminazuin Ab Rahim currently works as an Assistant Professor at Faculty of Engineering, International Islamic University Malaysai after finishing her PhD in Engineering (MEMS \& Nanoelectronics) from Institute of Microengineering and Nanoelectronics (IMEN), Universiti Kebangsaan Malaysia in 2012. Back in 1999, she was a former graduate from Universiti Sains Malaysia in Electrical \& Electronic Engineering (Microelectronics) before continuing her studies at Universiti Kebangsaan Malaysia in MSc. Microelectronics in 2004. She obtained an industrial exposure from Delphi Packard Electric (M) Sdn Bhd from1999 to 2001 where she worked as a Quality Engineer. Her research areas are related to MEMS device and fabrication where she was exposed to cleanroom-associated fabrication process while working on her $\mathrm{PhD}$ research on development of MEMS cantilever-based sensor. Her other research areas include piezoelectric energy harvester and biosensor.

Norfarahidah Za'bah currently works as an Assistant Professor at Faculty of Engineering, International Islamic University Malaysia after finishing her $\mathrm{PhD}$ in Engineering from Newcastle University in 2012. Back in 1999, she was a former graduate from Universiti Tenaga Nasional in Electrical \& Electronic Engineering (Electronics) before continuing her studies at Newcastle University in MSc. Microelectronics in 2004. Her research areas are related to Manufacturing and Production Engineering, Nano-elecronics, Applied Sciences and Technologies, Fabrication Technology.

Norazlina Saidin currently works as an Assistant Professor at Faculty of Engineering, International Islamic University Malaysia after finishing her $\mathrm{PhD}$ in Engineering from University of Malaya in 2015. Back in 2005, she was a former graduate from University of Malaya in Telecommunications Engineering before continuing her studies in MSc. Eng (Telecommunications) in 2010. Her research areas are related to Optical Fiber Laser and Amplifier, Fiber Optic Sensor. 